\title{
Experimental study of open-channel flow with partial double-layered vegetation
}

\author{
Xiaonan Tang ${ }^{1 *}$, Hamidrez Rahimi ${ }^{1}$, Prateek Singh ${ }^{1}$, Zishun $\mathrm{Wei}^{1}$, Yuxuan Wang ${ }^{1}$, Yufan \\ Zhao $^{1}$, Qiangshuai $\mathrm{Lu}^{1}$
}

${ }^{1}$ Department of Civil Engineering, Xián Jiaotong-Liverpool University, 111 Renái Road, Suzhou

Dushu Lake Higher Education Town, Jiangsu Province, China, 215123

\begin{abstract}
Many rivers and wetlands have vegetation. The effect of riparian vegetation on ecological and flow process in channels has become increasingly important in river flood risk and aquatic environmental management. Most previous studies have been done on the flow structure of vegetation of the same height which is not realistic in natural rivers. There are only a few studies on flows with a mixing array of short and tall vegetation under either submerged or emergent flow condition. This paper is to undertake a novel experimental study on a flow with double-layered vegetation under submerged and emergent conditions, which often occur in most rivers. Two different heights of dowels, $10 \mathrm{~cm}$ and $20 \mathrm{~cm}$, were used in the water flume to represent the short and tall vegetation respectively, and they were allocated on one side of the flume. Experiments in two flow depths were undertaken to represent different submergence ratios of vegetation, and velocities at various locations were measured by Acoustic Doppler Velocimetry (ADV) and propeller velocimetry. Experimental results show that the velocity profile is almost uniform within the depth of short vegetation in different configurations. The velocity starts to increase in the region near the edge of short vegetation, and then followed by a rapid increase through the height of tall vegetation to the free surface. Meanwhile, a strange shear layer exists laterally between vegetation and non-vegetation, showing that the vegetation significantly reduces the velocity of flow.
\end{abstract}

\section{Introduction}

In natural rivers and wetlands, vegetation widely exists; particularly various types of vegetation grow along the rivers. The riparian vegetation will increase the flow resistance and reduce the velocity of flow due to the additional drag generated by the vegetation. Thus, the decrease of the mean velocity will not only lead to significant changes in physical and biological processes in aquatic environments, but also cause morphological changes of channel bed. It has drawn many studies on the flow mechanics of vegetated flows and their effect, with the focus on the evaluation of flow velocity and resistance ([1]-[10]). These studies have mainly focused on vegetation with the same height under either emergent or

\footnotetext{
*Corresponding author: xiao.tang@xjtlue.edu.cn; xiaonan.tang@liverpool.ac.uk
} 
submerged flow conditions, which is not as real as that in natural rivers and channels. Although there are only a few studies on channel flows with an array of short and tall vegetation together [17,19], these studies are either in submerged or emergent flow conditions. In fact, vegetation in most rivers and natural channels has different heights and experiences both emergent and submerged conditions.

In open-channel flows without vegetation, the vertical velocity profile can be approximated to be logarithmic [11]. When vegetation exists, the velocity profile is expected to be changed due to the additional drag of vegetation on the flow. In the cases of emergent vegetation, the velocity profile is mostly uniform over the depth ([12]-[13]). However, in the cases of submerged vegetation, the velocity profile is S-shaped ([1], [3], [14]-[15]). In both cases, the flow velocity within the vegetation layer is significant smaller than that in the nonvegetated surface layer. Due to the interaction between surface and vegetation layers, the submerged condition becomes more complex than the emergent condition [13].

To explore the characteristic of flow with submerged vegetation, Liu et al. (2008) [16] did some experiments by rigid dowels (diameter $d=6.35 \mathrm{~mm}$ ) and measured flow velocities using LDV (Laser Doppler Velocimetry) at multiple locations. Their results indicated that flow characteristics inside the arrays of submerged vegetation are similar to those observed in the emergent cases. The velocity is nearly constant in the vegetation layer and follows by a rapid increase in the mixing layer near the top of vegetation (Fig. 1).

(a)

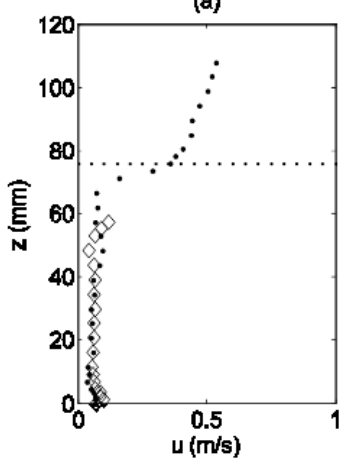

(b)

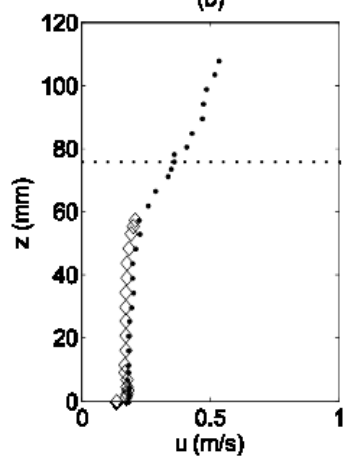

(c)

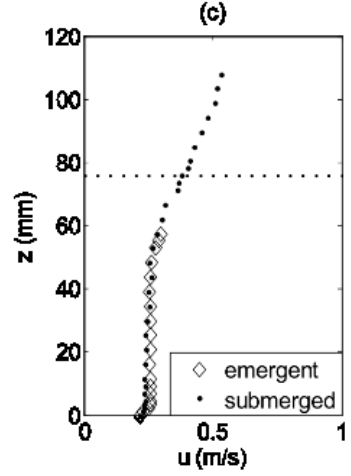

Fig.1. Velocity comparison between submerged and emergent conditions for the experiment with staggered vegetation with $s$ (spacing)/d=5 at (a) location 1 ( $1 d$ behind the dowel), (b) location 3 ( $4 d$ behind the dowel), and (c) location 5 ( $4 d$ behind and between the dowels (after Ref. [16]).

Meanwhile, the flow profile changes significantly depending on the measurement location in relation to the vegetation. Acquiring velocity data at multiple locations within a vegetation array is important, which will help to understand the characteristics of flow and its variation in the vegetation region. Most previous studies focus on flow through an emergent or submerged vegetation array. In natural environments, multiple vegetation layers exist from grasses to shrubs or trees. Examining how multiple layers of vegetation affects the flow is important for understanding the physical processes involved.

In this paper, a novel experiment has been setup in a rectangular channel with only one side having double-layered vegetation, the detailed velocities at various locations were measured by ADV (Acoustic Doppler Velocimetry) and propeller velocimetry, which aims to study the characteristics of flow in vegetation and non-vegetation. Particularly, both vertical velocity profiles in the vegetation and lateral velocity distribution cross the channel were presented in order to shed light on the impact of vegetation on the flow with doublelayered vegetation. 


\section{Experimental method}

All the tests were undertaken at the hydraulic laboratory in XJTLU (Xián Jiaotong-Liverpool University), in a $20 \mathrm{~m}$ long by $0.76 \mathrm{~m}$ wide straight rectangular channel at a slope of 0.003 (Fig.2a). The vegetation was modelled by $6.35 \mathrm{~mm}$ diameter circular plastic dowel with two different heights of 0.1 and $0.2 \mathrm{~m}$, which represent the short and tall vegetation, respectively. Both the short and tall dowels are staggered with spacing $(s)$ between the centers of dowels of $31.75 \mathrm{~mm}$. A $10 \mathrm{~mm}$ thick and $40 \mathrm{~cm}$ wide plate with holes is placed at the flume bottom to hold the dowels (simulated as rigid vegetation) (Fig.2b). Thus, the vegetated session of $6 \mathrm{~m}$ long covers one side of the flume, at $5 \mathrm{~m}$ away from the entrance of flume.

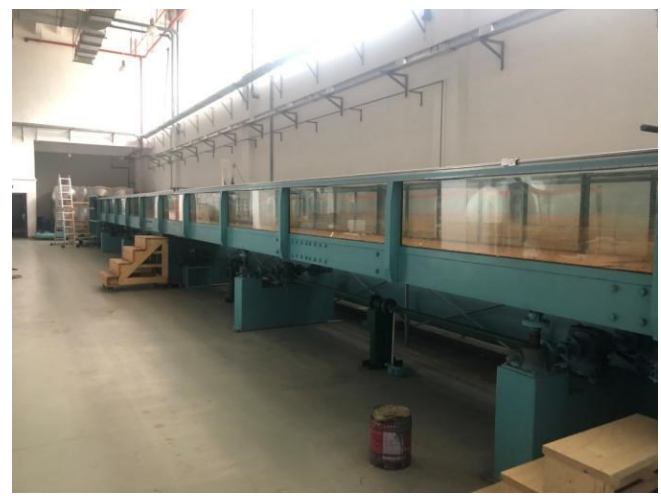

(a) Flume

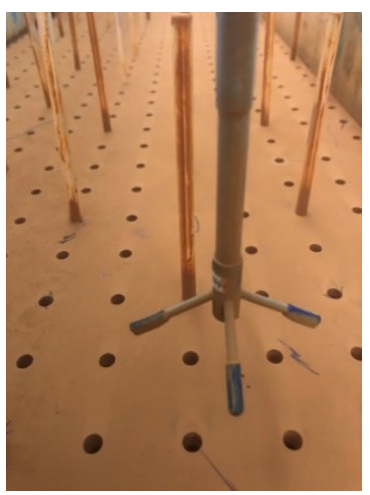

(b) Acoustic Doppler Velocimetry

Fig. 2. Water flume and Acoustic Doppler Velocimetry (ADV).

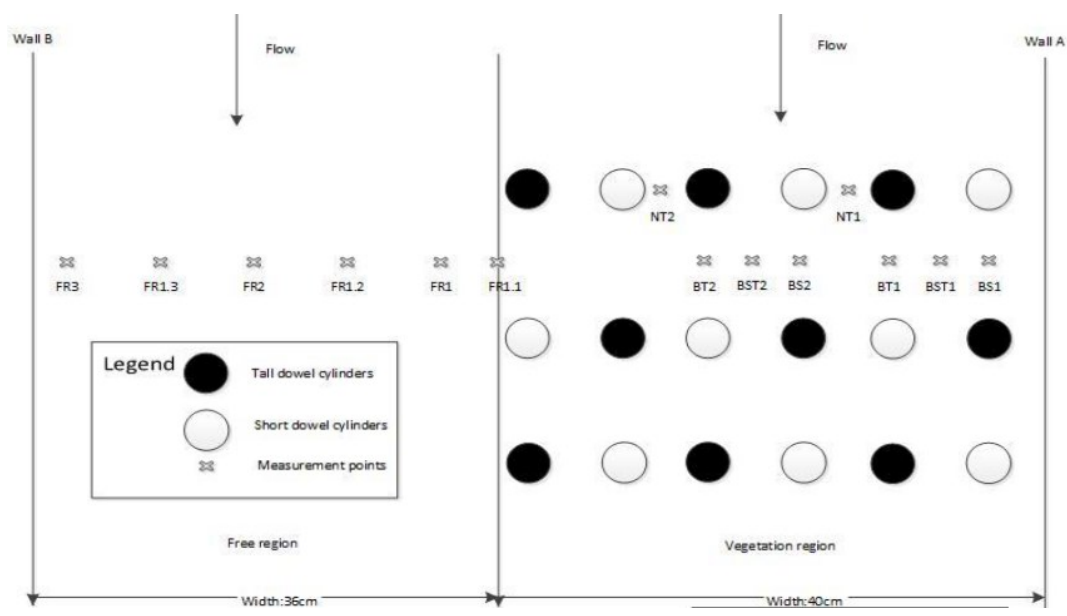

Fig.3. Dowel arrangement.

\subsection{Measurement}

Different measurement locations were selected to evaluate the flow characteristics in different regions of the vegetation portion (Fig. 3). To measure the velocity, two main measurement devices were used. For the top 5-6 cm of the flow, the velocity was measured by the propeller velocimetry; otherwise it was done by Nortek Micro-ADV to complete the measurement (Fig.2b). In some locations where the signal noise ratio is below the standard values or the position is not reachable by $\mathrm{ADV}$, which requires at least $5 \mathrm{~cm}$ above the bed 
or below the water surface, the propeller velocimetry was used. The ADV velocity data are filtered by WinADV software for highly correlated datasets. All the measurements locations are at the cross section 8 meters downstream from the flume entrance, which is 3 meters away from the beginning of vegetation plates.

In the experiment, two flow depths of 15 and $22.4 \mathrm{~cm}$ were set up. Their corresponding discharge is $67.83 \mathrm{~L} / \mathrm{s}$ and $67.50 \mathrm{~L} / \mathrm{s}$. For the depth of $15 \mathrm{~cm}$, the short dowels are submerged while tall ones are emergent. On the contrary, for the depth of $22.4 \mathrm{~cm}$, both types of dowels are in fully submerged conditions. Thus, a total of 14 locations for each experiment are selected as the measurement points, as shown in Fig.3.

\subsection{Measurement locations}

To help understand the results, the measured points are coded in the following way: for instance, if the measurement location is behind the tall dowel, it would be named as BT, while NT means the location next to the tall dowel. The notations for other letters are as follows: $\mathrm{BST}=$ behind and side away from the tall dowel, FR $=$ free region. The specific locations of the measurement points are shown in Table 1 . The velocity of the flow was measured in an interval of 1 or $2 \mathrm{~cm}$ along the vertical.

Table 1. Specific locations of measurement points

\begin{tabular}{|l|l|l|l|}
\hline \multicolumn{2}{|c|}{ Vegetation region } & \multicolumn{2}{c|}{ Free region } \\
\hline Measurement point & Distance to wall A $(\mathrm{cm})$ & Measurement point & Distance to wall A $(\mathrm{cm})$ \\
\hline BS1 & 7.5 & NT2 & 24.5 \\
\hline BST1 & 9.0 & FR1.1 & 40.0 \\
\hline BT1 & 10.5 & FR1 & 42.5 \\
\hline NT1 & 13.0 & FR1.2 & 49.0 \\
\hline BS2 & 20.0 & FR2 & 55.5 \\
\hline BST2 & 21.5 & FR1.3 & 62.0 \\
\hline BT2 & 23.0 & FR3 & 68.5 \\
\hline
\end{tabular}

\section{Results and discussion}

\subsection{Vertical velocity profiles}

The experimental data under two conditions are presented as follows:

Fig. 4(a) shows the vertical velocity profiles measured at different locations for the case at the flow depth of $15 \mathrm{~cm}$, i.e. the short vegetation is submerged but the tall vegetation is emergent. This figure indicates that the velocity within the short vegetation has almost constant values followed by a slight increase at the edge of short vegetation. Similar results were observed by Liu et al. [17].

The data of vertical velocity in Fig. 4(a) also show a clear different distribution in the zones below and above the top of short vegetation $(10 \mathrm{~cm}$ in this study). In the lower zone, the velocity has little relationship with the change of height. The inflection appears around at $10 \mathrm{~cm}$ and the velocity begins to increase rapidly above it.

For the fully submerged case of $22.4 \mathrm{~cm}$ where both short and tall dowels are submerged, the velocity profiles at all locations are shown in Fig. 4(b). It appears that the overall velocity becomes smaller compared with that of half-submerged situation (i.e. $\mathrm{H}=15 \mathrm{~cm}$ ).

In the fully submerged case, Fig. 4(b) shows that the velocity profile can be divided into three zones: (1) Lower zone from the bottom to near the top of short vegetation, the profile 
is almost constant, similar to that in the half-submerged situation. (2) Middle zone between the tops of short and tall vegetation, the velocity almost remains a constant in the bottom half of the zone, and then increases gradually. (3) Upper zone (free surface zone), the velocity continuously increases to the surface. Interestingly, a sudden change of velocity occurs at above $\mathrm{z}=10 \mathrm{~cm}$ (the height of short vegetation), and then the velocity rapidly increases from this point and remains constant until the edge of tall vegetation. In the upper zone, the velocity profile likes a 'J' shape. This velocity profile may follow a semi-logarithmic function, which means that the effect of the drag of vegetation is less on the flow in this zone [18].
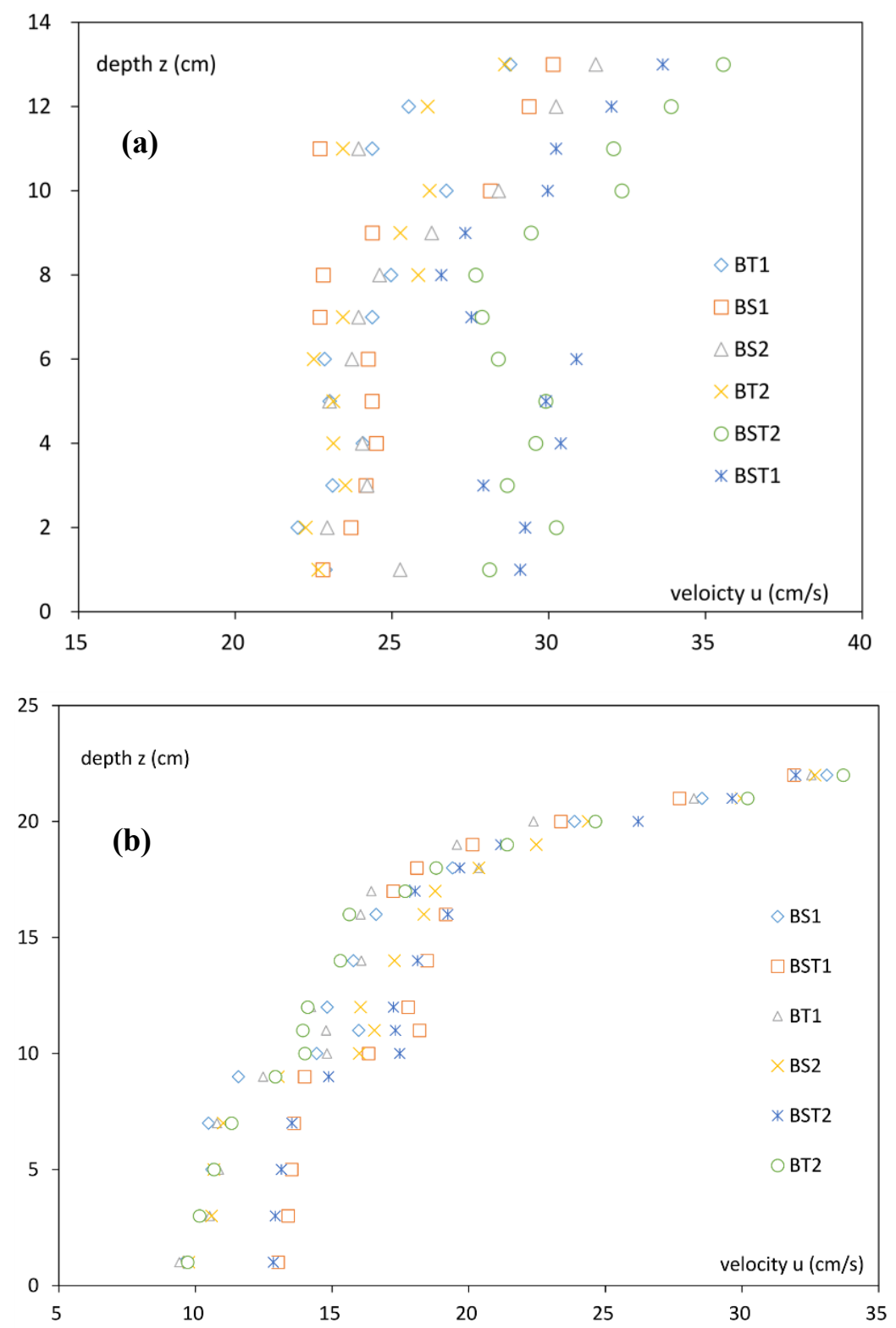

Fig. 4. Vertical velocity profiles inside the vegetation for the flow depth of: (a) $15 \mathrm{~cm}$, (b) $22.4 \mathrm{~cm}$. 


\subsection{Lateral velocity distribution}

The lateral velocity distribution is shown in Fig.5. The vegetation region (left side) has a lower average velocity compared with the non-vegetation free region (right side). It clearly shows that the velocity increases rapidly from the vegetated region to the non-vegetation region, with a significant transition along the interface between the two regions. This indicates that a strong momentum exchange takes place along the interface between the two regions. The reason is mainly due to the velocity difference between the two regions, where fast moving flow is in the non-vegetation region while the slow moving flow is in the vegetated region.

Furthermore, when the water depth changes, the flow in the vegetation region seems to have less influence than in the free region. The reason may be that the influence of depth on the resistance in the vegetated region is relatively small compared with that in the free region.

The proportion of discharge in each region can be calculated based on the lateral velocity distribution. The calculated results show that the discharge percentage in the vegetation part of channel is much higher (almost 200\% larger) than in the free part of channel (Fig.6). In other words, the discharge in the vegetated zone is about $1 / 3$ of the discharge in the free zone.

In addition, it appears that the discharge percentage in the free region slightly decreases from $77 \%$ to $73 \%$ as the flow depth increases from $15 \mathrm{~cm}$ to $22.4 \mathrm{~cm}$, whereas the discharge percentage in the vegetation part of channel increases from $23 \%$ to $27 \%$. In general, the ratio of discharge through the vegetation zone to that in free zone increases from 0.32 to 0.37 as increasing depth of flow from $15 \mathrm{~cm}$ to $22.4 \mathrm{~cm}$.

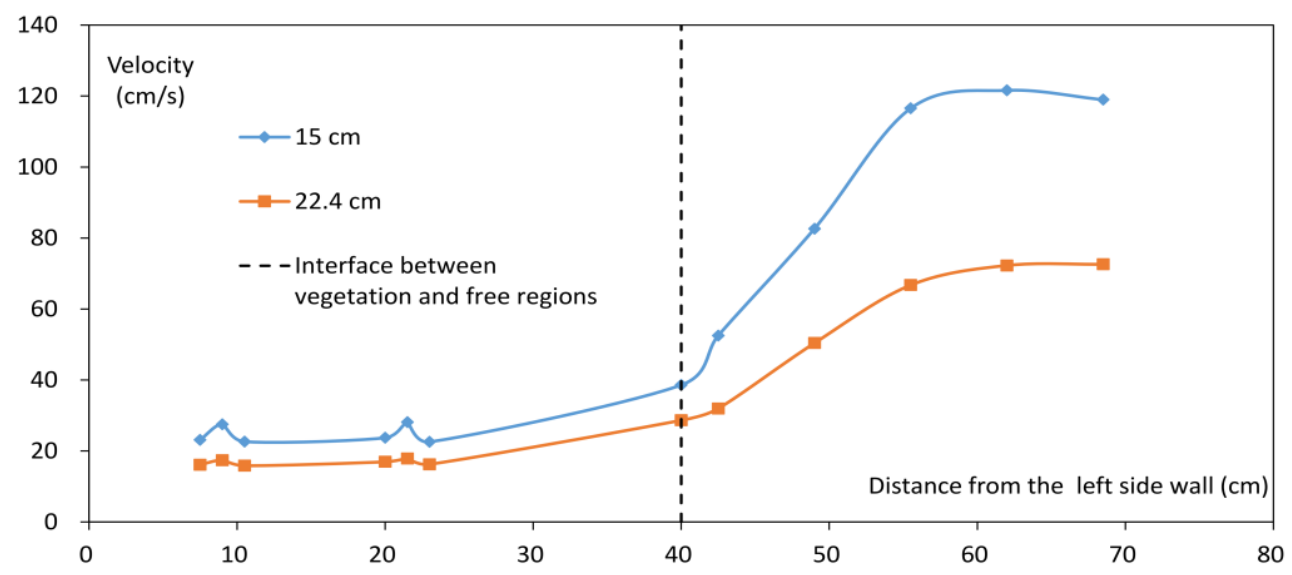

Fig. 5. Lateral velocity distribution.

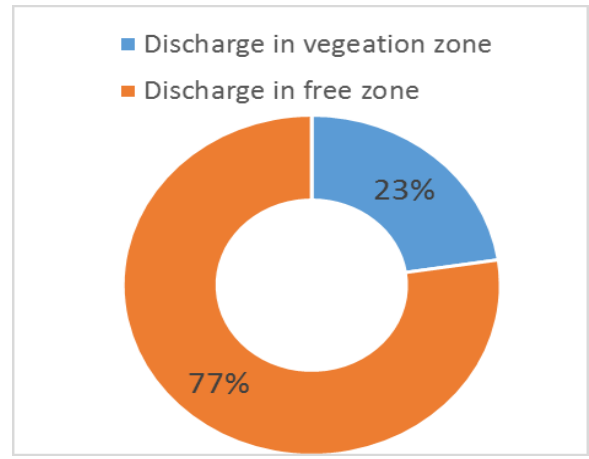

(a)

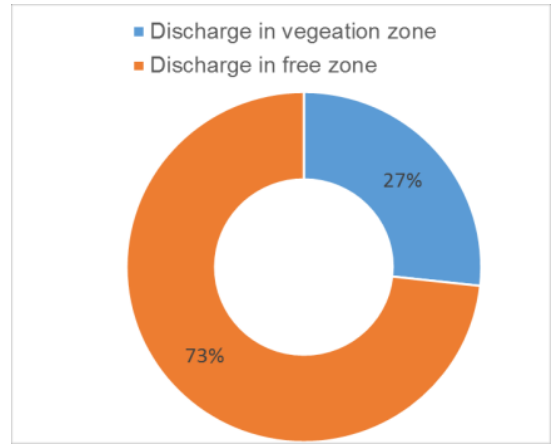

(b)

Fig. 6. Discharge percentage of each region for the flow depth of: (a) $15 \mathrm{~cm}$, (b) $22.4 \mathrm{~cm}$. 


\section{Conclusions}

The experimental study on the open-channel flow with partial double-layered vegetation shows significant effects of multiple mechanism within the depth of flow. The velocity decreases in the region of vegetation due to drag of vegetation, which affects channel conveyance. The results of measured velocity profile show that different vertical zones exist depending on the submergence of vegetation. The flow resistance appears high in the lower vegetation but decreases in the upper half of flow. The results indicate that the effect of vegetation become significant to the distribution of velocity during high flow, such as flood, storm and flash typhoon.

\section{References}

1. N. Kouwen,T.E. Unny, H.M.Hill, J. Irrigation \& Drainage Div. 95(IR2), 329-342 (1969).

2. H. M. Nepf, E. R. Vivoni, J. Geophy. Res. - Oceans, 105(C12), 28547-28557 (2000).

3. F.G. Carollo,V. Ferro, D.Termini, J. Hydraulic Eng., 128(7), 664-673 (2002).

4. I. Nezu, M. Sanjou, J. Hydro-Env. Res. 2(2), 62-90(2008).

5. J. Jarvela, J. Hydrology, 269(1-2), 44-54 (2002).

6. X, Tang, D.W.Knight, M.Sterling, Proc. ICE: Eng. Comp. Mech. 164 (2): 91-102 (2011).

7. X. Tang, Water \& Environment J., DOI:10.1111/wej.12434 (2018).

8. X. Tang, S. Ali, In Proc. of 35th IAHR World Congress, 4 (B1), A11218, 1-12, Sept. 813(2013), Chengdu, China. ISBN: 978-7-89414-588-8.

9. X. Tang, D.W. Knight, J. Science in China Series E: Technological Sciences, 52(11): 3357-3362 (2009).

10. X. Tang, M. Sterling, D.W. Knight, In River Flow 2010, 1, 469-476, Dittrich, et al. (Editors), Brundesanstalt fur Wasserbau, Germany, ISBN: 978-3-939230-00-7 (2010).

11. I. Nezu, H. Nakagawa, Turbulence in open-channel flows, IAHR Monograph Ser., Balkema Publishers, Rotterdam, Netherlands (1993).

12. T. Tsujimoto, T. Kitamura, KHL Communication, 1, 43-55 (1990).

13. B. M. Stone, H. T. Shen, J. Hydraulic Eng. 128(5), 500-506 (2002).

14. D. M. Temple, J. Hydraulic Eng. 112(3), 193-205 (1986).

15. S. Ikeda, M. Kanazawa, J. Hydraulic Eng. 122(11), 634-640 (1996).

16. D.Liu, P.Diplas, J.D.Fairbanks, C.C.Hodges, J. Geophy. Res.- Earth Surface, 113 (2008).

17. D. Liu, P. Diplas, C.C. Hodges, J.D. Fairbanks, Geomorphology 116, 286-296 (2010).

18. Y. Wang, Study on the characteristics of open channel flow with double layer vegetation, PhD dissertation, Hehai University (2017).

19. N. Anjum, U. Ghani, G.A. Pasha, A. Latif, T. Sultan, S. Ali, Water 10 (1), 75 (2018). 